Volume 9, No.5, September - October 2020

International Journal of Advanced Trends in Computer Science and Engineering

Available Online at http://www.warse.org/IJATCSE/static/pdf/file/ijatcse215952020.pdf

https://doi.org/10.30534/ijatcse/2020/215952020

\title{
Model of induction heaters of the grain drying process
}

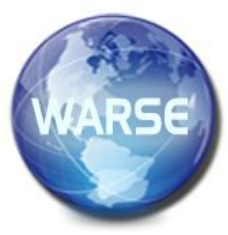

\author{
Sagyndikova A.J. ${ }^{1}$, Isembergenov N.T. ${ }^{2}$, Begimbetova A.S. $^{3}$.Tergemes K.T. ${ }^{4}$ \\ ${ }^{1}$ Gumarbek Daukeev Almaty University of Energy and Communications, Department of Energy supply and \\ renewable energy sources, Almaty, Kazakhstan, sagyndikova_aigul@mail.ru \\ ${ }^{2}$ Gumarbek Daukeev Almaty University of Energy and Communications, Department of Radio Engineering, \\ electronics and telecommunications, Almaty, Kazakhstan, isembergenov@mail.ru \\ ${ }^{3}$ Gumarbek Daukeev Almaty University of Energy and Communications, Department Engineering ecology \\ and labor safety, Almaty, Kazakhstan, a.begimbetova@aues.kz \\ ${ }^{4}$ Gumarbek Daukeev Almaty University of Energy and Communications, Department of Energy supply and \\ renewable energy sources, Almaty, Kazakhstan, k.tergemes@@aues.kz
}

\begin{abstract}
The article presents a model of the induction method of grain drying related to energy saving. Increasing the efficiency of the process of heating grain material and reducing energy consumption is due to the fact that there is a uniform distribution of moisture in the dried product. Induction heaters for the grain drying process have the advantage that there is no heat transfer from the heater. Increasing the degree of heating of environmentally friendly air.
\end{abstract}

Key words: grain, induction heater, experiment, heat treatment, idealized contact-type plant for heat treatment of grain, grain drying, helicoidal surface, regression model.

\section{INTRODUCTION}

The possibility of using the contact method of heat transfer for heating grain during its heat treatment has been confirmed by a number of studies[1]. Thus, contact heating of raw materials is used in flour and grain mills, mainly for heating grain and slightly reducing humidity when preparing it for processing. Under the contact surface, we used the heated surface of the drying (heat) chamber, with which the grain layer is in direct contact[2]. Therefore, it is possible to clarify the theory of heat treatment of grain in relation to the developed contact electric heat exchanger.

The speed of the contact method of heat transfer depends on the heating temperature of the contact surface, the thickness of the processed grain layer, as well as the time of contact of the grain with the heating surface (exposure to heat) [3].

\subsection{The purpose of the article}

In order to increase the efficiency of grain heat treatment processes, increase the throughput capacity of the plant, ensure a more uniform distribution of grain over the heating surface (increase the filling coefficient), and therefore, for a more uniform heating of the processed grain layer, we have proposed a new method for studying grain drying modes.[4].

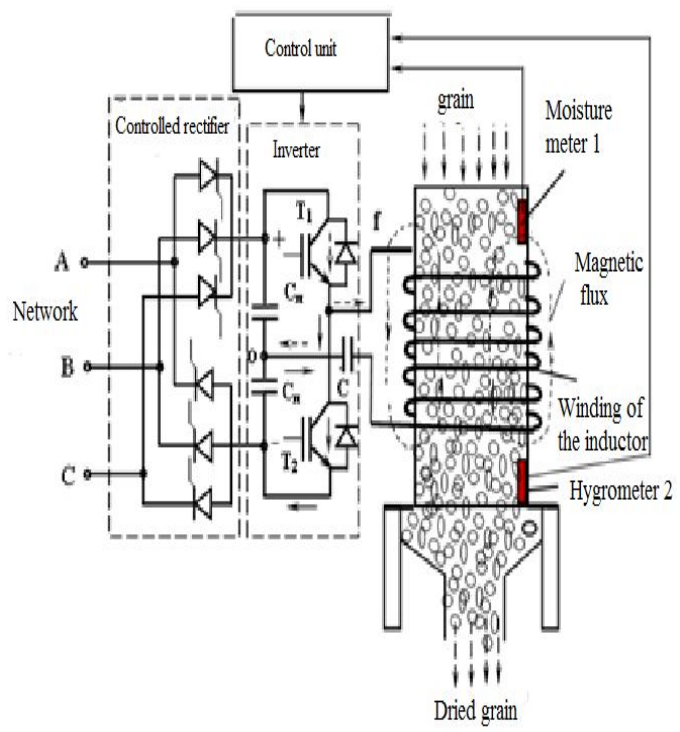

Figure 1: Method and device for induction grain drying

Direct heating of the grain material itself is carried out due to the fact that the loading of the drying chamber occurs under the influence of gravity. The drying chamber is made in the form of a cylinder, on the outer surface of which an electric winding is wound. It also has moisture meters installed to control the humidity in the drying chamber, Figure 1. The control unit installed outside the drying chamber regulates the heating level of the temperature in the drying chamber. The invention relates to agricultural engineering and can be used for drying not very large portions of grain with environmentally friendly air at a temperature of $50-75^{\circ}$ C.

\section{LETERATURE REVIEW}

The structural basis of a contact grain dryer by means of an induction heater is a heat exchanger with electric heat sources. The design element of a contact electrical installation for heat treatment of grain is a heat exchanger with electric heat sources and a transporting 
working body to ensure the continuity of the process, as well as the uniform distribution of the processed grain over the heating surface with constant mixing of the grain layer[5].

We highlight certain requirements for the normal flow of heat treatment processes (drying, roasting, heating, etc.). in relation to the contact method of heat supply, these requirements are as follows: uniform heat supply to the processed grain; ensuring the maximum possible contact area of the grain surface undergoing heat treatment; constant removal of moisture released from the grain (i.e., constant supply of dry and wet drying agent); moving and simultaneous mixing of the grain layer to avoid local overheating of the grains.

So, the processes of grain heat treatment in a contact heat exchanger are characterized by a combination of various factors, each of which directly or indirectly affects the efficiency of the developed installation as a whole [6].

\section{MODELS AND METODS}

The technological scheme of the grain dryer is shown in Figure 2a. The installation contains a high-frequency generator, an exciting winding, an envelope of the cylinder in which the screw with a helical surface is located[3,6].

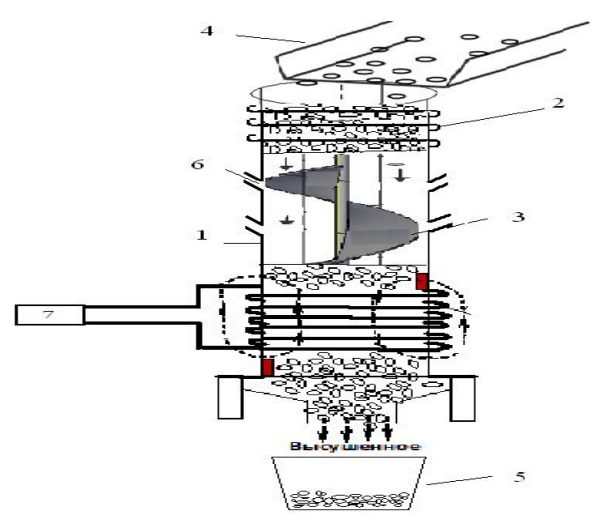

a)

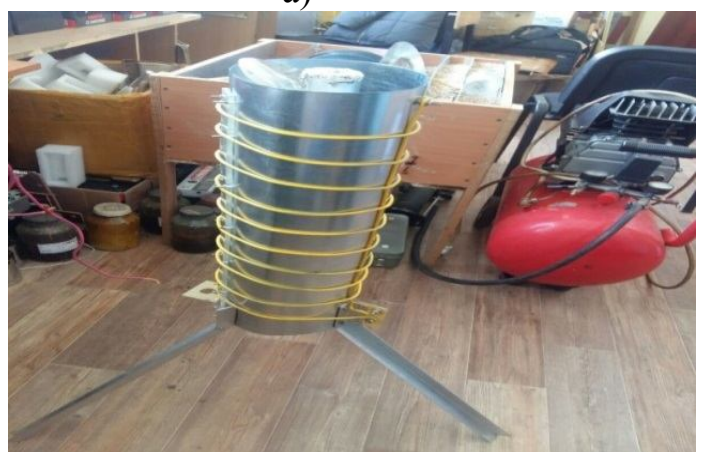

b)

Figure 2: a) technological scheme of the grain dryer,b) layout of the laboratory installation

1-cylindrical casing, 2 - electric winding, 3 -conveying screw, 4 - loading tray, 5 - unloading lath, 6 - air outlet
Figure 2b shows the layout of the laboratory installation, which is made according to the technological scheme.

The following indicators served as criteria for evaluating the operation of the grain drying unit: wheat grain with a moisture content of $13-15 \%$ intended for long-term storage. In the first case, the heating temperature of the grain was taken into account, and in the second - the grain layer. The experiments were carried out on a laboratory - experimental setup (Figure 2b). According to agrotechnical requirements, wheat grain has a humidity of $25-28 \%$ during harvesting, and after drying it should have 13-15\% humidity.Ecofriendly hot air is supplied.

Inside this cylinder there is a fixed conveying screw (3), which is filled with grain from the hopper from the upper part. Due to gravitational forces, the grain moves down the helical surface. Here there is one feature - the helical surface must have a variable pitch, decreasing from the top to the bottom[7].

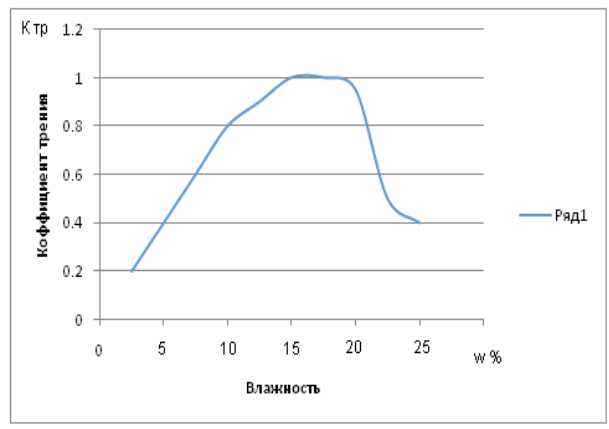

Figure 3: Dependence of the coefficient of friction of the grain against moisture

This is due to the fact that as the grain dries, the coefficient of friction of the grain on the material of the screw surface decreases. In General, the coefficient of grain friction on the material initially increases with increasing humidity, because there is an adhesion effect [8,9]. Then, when a certain humidity is reached, it begins to decrease, since moisture forms a lubricating film between the grain and the surface material (Figure 3 ). With a further increase in humidity, such a mixed medium, grain and moisture passes into a quasi-liquid state and the coefficient of friction drops sharply.

\subsection{Results of computation experiments}

We can see from Figure 3 that in the area of real grain humidity $(5-25 \%)$, this dependence is linear and has the following form.

$$
\mathrm{K}_{\mathrm{TP}}=0,010 W+0.331(1)
$$

where $\mathrm{K}_{\mathrm{TR}}$ - coefficient of friction, $\mathrm{W}$ - grain moisture

The initial velocity of the grain in contact with the helical surface is determined from the simplest equation of free fall 


$$
V_{0}=\sqrt{2 g h_{0}}(
$$

where $\mathrm{h}_{0}$ - is the distance from the output part of the loaded hopper to the horizontal cross - section plane of the helical surface (Figure 2).

In formula 1, the air resistance is neglected, since the grain flow rate is small.

Grain, once on the helical surface, should not immediately slide down this surface, because the coefficient of friction $\mathrm{K}_{\mathrm{rt} 0}>\mathrm{L}_{\mathrm{i} 1}$ is greater than the angle of rise of the helical surface. Only after heating the moisture in the grain and partially reducing the humidity, the coefficient of friction will begin to decrease, and the grain moves down, but then it will stop, because in this part $\mathrm{K}_{\mathrm{rt0}}>\mathrm{L}_{\mathrm{il}}$, etc., until the grain reaches the required humidity, [10].

During individual drying, the moisture in the grain is heated and evaporated, which reduces the moisture content of the grain at the moment and proportionally reduces the coefficient of friction [11]. When the coefficient of friction reaches a value greater than tg of the angle of inclination of the helicoid, the grain begins to move down again and the process is repeated.

\subsection{Problem solution}

The speed of grain movement in the vertical plane should not be very small (Figure 4), because otherwise the grain will overheat (due to boiling water in the grain), but it should not be large, considered in $[5,12,13,14]$, the authors recommend drying with $\mathrm{RF}$ currents for no more than 2 minutes (120sec), otherwise the germination of the grain will decrease. At the same time, the exposure time of the magneticelectric field to the grain is reduced, and it will come out insufficiently dried.

Under such conditions, the spatial movement of the grain, when there is a centrifugal force pressing the grain against the wall of the casing, can be ignored. Accordingly, we neglect the Coriolis acceleration. The problem is reduced to finding the generating helical surface projected on the X-Y plane[16].

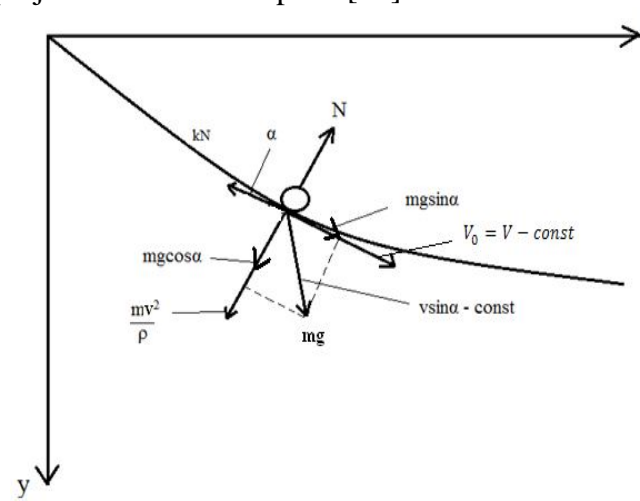

Figure 4: Forces acting on the grain moving along the screw windings
We set the condition for the constant speed of grain movement along the forming helix, i.e.

$$
V=V_{0}=\text { const }
$$

where $\mathrm{V}_{0}$ - is the initial grain velocity

You need to determine the shape of this generator. Equation (2) will take the form:

$$
m \frac{d v}{d t}=m g \sin \alpha-\kappa N=0 \text { (4) }
$$

Substituting equation (3) in (5) we have:

Given that

$$
\begin{aligned}
& m g \sin \alpha-k m g \cos \alpha+k m \frac{V_{0}^{2}}{\rho}=0 \\
& \sin \alpha=\frac{d y}{d s} ; \cos \alpha=\frac{d x}{d s} ; \rho=\frac{d s}{d \alpha}(5)
\end{aligned}
$$

$$
d \alpha=\frac{y^{\prime} d x}{1+y^{2}}
$$

then equation (5) will change the form:

$$
y\left(y^{\prime}-k\right)+k V_{0}^{2} \frac{y^{\prime}}{1+y^{2}}=0(6)
$$

Thus, we obtain a differential equation of the 2 nd order of the forming helical surface, along which the grain, drying, would move at a constant speed.

$$
y^{\prime}-\frac{g}{k V_{0}^{2}}\left(y^{\prime}-k\right)+\left(1+y^{2}\right)=0 \text { (7) }
$$

To solve this equation, we introduce the substitution

and equation (7) will take the form:

$$
Y^{1}=g(8)
$$

$$
\frac{d g}{d x}=\frac{g}{k V_{0}^{2}}(g-k)\left(1+g^{2}\right)(9)
$$

or

$$
d x=\frac{k V_{0}^{2} d g}{g(g-k)\left(1+g^{2}\right)}
$$

Integrating we have:

$$
\int d x=h_{0} \int \frac{d g}{\left(1+g^{2}\right)(b g-1)}(11)
$$

where: $a=h_{0}=\frac{V_{0}^{2}}{g}$ - distance from the grain bin to the dryer neck;

$$
b=\frac{1}{k}(12)
$$

To integrate (12), we decompose the fraction into two elements: 


$$
\frac{1}{\left(1+g^{2}\right)(b g-1)}=\frac{A g+B}{1+g^{2}}+\frac{c}{b g-1}
$$

Simplifyingwehave:

$$
A b g^{2}-A g+B b g+C+C g^{2}=1
$$

Equating the coefficients with equal powers, we come to the expressions:

$$
A=\frac{-b}{1+b^{2}} ; B=-\frac{1}{1+b^{2}} ; A=\frac{b^{2}}{1+b^{2}} ;
$$

Substituting in equation (12) we get:

$$
x=a \frac{-b}{1+b^{2}} \int \frac{g d g}{1+g^{2}}-\frac{a}{1+b^{2}} \int \frac{d g}{1+g^{2}}+\frac{a b^{2}}{1+b^{2}} \int \frac{d g}{b g-1}+C
$$

where $\mathrm{C} 1$ is a constant determined from the boundary conditions (3).

Integrating equation (14) in parts:

$$
x=\frac{a b}{1+b^{2}} \ln \frac{b q-1}{\sqrt{1+q^{2}}}-\frac{a}{1+b^{2}} \operatorname{arctg} q+C^{(15)}
$$

The constant $\mathrm{C}_{1}$ is determined from the visual conditions for $\mathrm{x}=0 ; \mathrm{q}_{0}=\mathrm{y}^{1}=\mathrm{V}_{0}$;

From here: $C_{1}=\frac{a}{1+b^{2}} \operatorname{arctg} q_{0}-\frac{a b}{1+b^{2}}-\ln \frac{b q_{0}}{\sqrt{1+q_{0}}}$

Equation (15) is converted to the form:

$$
x=\frac{a b}{1+b^{2}} \ln \left[\frac{(b q-1) \sqrt{1+V_{0}^{2}}}{\left(b V_{0}-1\right) \sqrt{1+q}}\right]+\frac{a}{1+b^{2}}\left(\operatorname{arctg} V_{0}-\operatorname{arctg} q\right)
$$

To determine the second cartesian coordinate $\mathrm{x}$, we refer to the expression:

$\frac{d y}{d x}=q$, substituting the value of $\mathrm{x}$ from (16)

Receive $d y=\frac{a q d q}{\left(1+q^{2}\right)(b d-1)}$

Decomposing the fraction into elements, we have:

$$
d y=\frac{a}{1+b^{2}}\left(-\frac{q}{1+q^{2}}+\frac{b}{1+q^{2}}+\frac{b}{b q-1}\right) d q
$$

By integrating we get:

$$
y=\frac{a}{1+b^{2}}\left(\ln \frac{b q-1}{\sqrt{1+q^{2}}}+\operatorname{barctg} q\right)+C ;(18)
$$

The constant $\mathrm{C} 2$ is determined from the boundary conditions

by $q=q_{0}=V_{\text {ouy }}=0$

$$
C_{2}=-\frac{a}{1+b^{2}}\left(\ln \frac{b V_{0}-1}{\sqrt{1+V_{0}}}+\operatorname{barctg} V_{0}\right)
$$

And equation (18) will take the form

$$
y=\frac{a}{1+b^{2}}\left[\ln \left(\frac{\left(b q-1 \sqrt{1+V_{0}^{2}}\right)}{\left(b V_{0}-1\right) \sqrt{1+q^{2}}}+b\left(\operatorname{arctg} q-\operatorname{arctg} V_{0}\right)\right)\right]
$$

For the generatrix of a screw it is more convenient to consider it in polar coordinates

$$
\begin{aligned}
& \rho=\sqrt{y^{2}+x^{2}=\sqrt{\left(\frac{a}{1+b^{2}} \ln \left[\frac{(b q-1) \sqrt{1+V_{0}^{2}}}{\left(b V_{0}-1\right) \sqrt{1+q}}+\frac{a}{a^{2}+b^{2}}\left(\operatorname{arctg} V_{0}+\operatorname{arctg} q\right)\right]\right.}} ; \\
& +\left[\frac{a}{a^{2}+b^{2}}\left(\ln \frac{(b q-1) \sqrt{1+V_{0}^{2}}}{\sqrt{1+q^{2}}\left(b V-1_{0}\right)}\right)+b\left(\operatorname{arctg} q-\operatorname{arctg} V_{0}\right)\right]^{2}
\end{aligned}
$$

Given our condition that:

and also that

$$
y^{1}=0.01 w+0.33 ;(21)
$$

$$
b=\frac{1}{0.01 w+0.33} ; \text { and } a=h=\frac{V_{0}^{2}}{q}
$$

we will get the final dependence that determines the shape of the forming screw surface depending on the grain humidity and the distance from the hopper to the dryer neck[16].

$$
\begin{aligned}
& \rho=\sqrt{\left(\frac{a b}{1+b^{2}} \ln \left[\frac{(b q-1) \sqrt{1+V_{0}^{2}}}{\left(b V_{0}-1\right) \sqrt{1+q^{2}}}\right]\right.}+\frac{c}{1+b^{2}}\left(\operatorname{arctg} V_{0}-\operatorname{arctg} q\right)^{2}+ \\
& +\left[\frac{a}{1+b^{2}}\left(\ln \frac{(b q-1) \sqrt{1+V_{0}^{2}}}{\sqrt{1+q^{2}\left(b V_{0}-1\right)}}\right)+b\left(\operatorname{arctg} q-\operatorname{arctg} V_{0}\right)\right]^{2} ;
\end{aligned}
$$

After simplification, we come to the final function describing the desired generator in polar coordinates

$$
\rho=\frac{V_{0}^{2}}{q} \sqrt{\left(\frac{1}{1+\left(\frac{1}{0.01 w+0.33}\right)^{2}}\right)}\left[\ln \left(\frac{\left(\frac{\operatorname{tg} \alpha}{0.01 w+0.33}-1\right) \sqrt{1+V_{0}^{2}}}{\sqrt{1+\operatorname{tg} \alpha\left(\frac{V_{0}}{0.01 w+0.33}-1\right)}}\right)\right]+\left(\operatorname{arctg} V_{0}-a\right)^{2}
$$

For the engineering interpretation of equation 24, the authors calculated this function in Excel and here you can clearly see how the angle of inclination of the generating helix and its polar radius change depending on the humidity at the moment when moving along the helix inside the microwave drying emitter. In fact, we see that this screw has technologically feasible parameters for both the angle of the helix and the polar radius[17]. 
Thus, we have obtained the equation of the helicoid generatrix with a variable step depending on the initial velocity of the falling grain $\mathrm{V}_{0}$ and the grain humidity $\mathrm{W}$ at each moment of movement along the curve $\mathrm{f}$ $(\mathrm{p}, \alpha)$, where $\mathrm{p}$ and $\alpha$ change depending on the grain friction coefficient as a function of its humidity, Figure 5 .

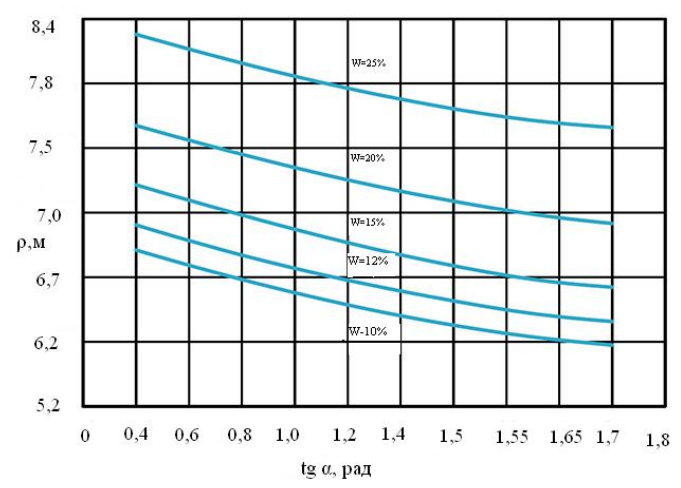

Figure 5:Dependence of the grain friction coefficient

When conducting a study of the grain drying process by means of induction heaters based on the use of multi - factor planning of the experiment, the goal was to obtain a simple model of the process: optimal parameters and operating modes of the working bodies of the grain drying plant, linking its efficiency with the most important factors. You can get environmentally friendly grain with high drying quality in very simple and inexpensive drying units.

\section{COMPUTATIONAL EXPERIMENTS}

A linear programming problem was formulated, and a model was obtained that is used as an objective function under the condition of the desired values. The Statistica 10 program processed the received data[6].Based on the results of the experiment, it was decided to start planning the experiment, as a result, a regression equation with free terms was found, and a decision was made about its adequacy.

After introducing the factors $X_{1}$ - heating temperature, $\mathrm{X}_{2}$-grain heating time, $\mathrm{X}_{3}$-grain layer thickness, we get the results of regression analysis (table 1).

Table1: Results of multivariate analysis of variance

\begin{tabular}{|c|c|c|c|c|c|}
\hline \multirow[t]{2}{*}{$\begin{array}{l}\mathrm{N}= \\
15\end{array}$} & \multicolumn{5}{|c|}{$\begin{array}{l}\text { RegressionSummaryforDependentVariable: } \\
\text { (Spreadsheet2) } \\
\mathrm{R}=, 29907896 \mathrm{RI}=, 08944823 \text { AdjustedRI= ------ } \\
\mathrm{F}(3,11)=, 36020 \mathrm{p}<, 78298 \text { Std.Error of estimate: } \\
3,9245\end{array}$} \\
\hline & $\mathrm{b}^{*}$ & $\begin{array}{l}\text { Std.Err } \\
\text {. of } b^{*}\end{array}$ & $\mathrm{~b}$ & $\begin{array}{l}\text { Std.Err. } \\
\text { of } b\end{array}$ & $\mathrm{t}(11)$ \\
\hline $\begin{array}{l}\text { Inter } \\
\text { cept }\end{array}$ & & & 19,215 & 2,6282 & $\begin{array}{l}7,31 \\
1\end{array}$ \\
\hline$X_{1}$ & $-0,38692$ & 1,3983 & $-0,082$ & 0,2985 & 0,27669 \\
\hline$X_{2}$ & 1,90107 & 2,1747 & 0,408 & 0,4676 & 0,87415 \\
\hline $\mathrm{X} 3$ & $-1,35943$ & 1,7934 & $-0,306$ & 0,4036 & 0,75800 \\
\hline
\end{tabular}

The results of multivariate analysis of variance show a certainty coefficient $\mathrm{R}^{2}=0.89$, also show that $89 \%$ of the $\mathrm{Y}$-axis change was controlled by factors $\mathrm{X}_{1}$ and $\mathrm{X}_{2}$, and describe a linear model. Coefficient in $\mathrm{B}_{0}=19.21$, $\mathrm{B}_{2}=-0.082, \mathrm{~B}_{3}=0.408, \mathrm{~B}_{4}=-0.306$, because $\mathrm{p}<0.782$ for three coefficients. The Fisher criterion $\mathrm{F}(2.13)=0.36$, which corresponds to a probability $\mathrm{p}<0.782$, shows that the model describes changes in $\mathrm{Y}$.

We get a regression model describing the surface (Figure6) in three-dimensional space[18].
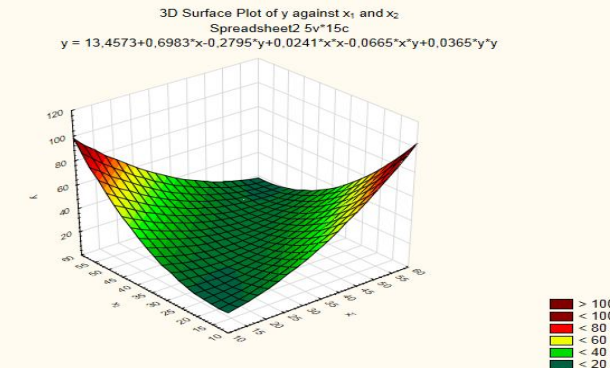

Figure 6: Three-dimensional model of the grain drying process

\section{DISCUSSION OF SIMULATION RESULTS}

The figure shows the area of change of factors $\mathrm{x}_{1}$ and $\mathrm{X}_{2}$ and the constant parameter $\mathrm{Y}$. According to the report of insignificant influence on the factor $X_{3}$, the result from (Figure 3 ) for $\mathrm{Y}$ is written in the following model:

$$
\begin{aligned}
& y=13.4573+0.6983 x-0.2795 y+0.0241 x_{1} x_{2}- \\
& 0.0665 x_{1} y+0.0365 y_{1} y
\end{aligned}
$$

Then the model changes in $\mathrm{Y}$ with $89 \%$, and the Fisher criterion $\mathrm{F}(2.13)=0.36$ corresponds to the probability $\mathrm{p}<0.782<0.05$, and shows that the result obtained is adequate. According to the data obtained (Figure 7), the normal probability graphs of the second degree are $X_{1}$ and $X_{2}$ (Figure 6). [17,19].

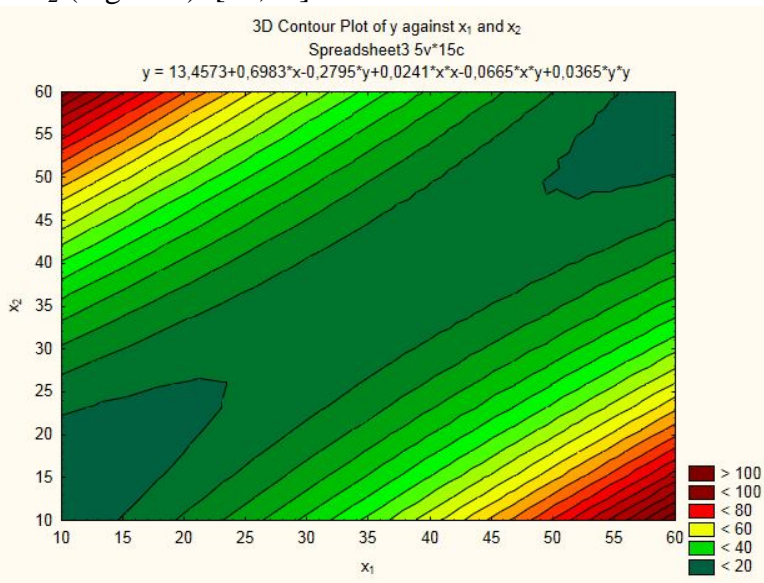

Figure 7: Normal probability graph for a given model 
Next, to get lines of the same response (Figure 4), using the Statistica 10 program, we translate the figures of the area of change of factors $\mathrm{X}_{1}$ and $\mathrm{X}_{2}$ into a $3 \mathrm{D}$ system[20,21].

Thus, based on the optimization results, we can conclude that the grain drying process is improved under the conditions allowed by the norm.

\section{Gratitudes}

The study and article done in the framework of advanced scientific and technical programs of the Department of agricultural engineering and technology of the Kazakh national research University, and the grant of the Republic of Kazakhstan "Sustainable development of agriculture and safety of agricultural products" IRN project AP05130184.

Two author's certificates were obtained: No. 97241 "Device for grain drying with screw conveyor", No. 91438 "Installation for grain drying»[3,6].

\section{CONCLUSIONS}

Currently, the possibility of effective use of electric heating for drying grain has been proven. Highfrequency grain dryers were designed, tested, and even put into practice. The grain that is dried in such installations meets all technological requirements, and in some cases surpassed the quality of grain dried in the traditional, convective way. Economic changes in our country have revealed the demand for miniaturization of plants, mini-grain dryers have been created, mobile grain dryers with relatively low power consumption, highly economical, easy to use and maintain, and most importantly - quite cheap. Providing environmentally friendly hot air and not requiring consumption, except for electricity, any heat carriers, will find its "niche" in a number of mobile and stationary grain drying units. This will also contribute to the simplicity of its design and operation and low cost.

\section{REFERENCES}

1. A. E. Baum. Drying grain/ A. E. Baum, V. A. Rezchikov.-M.: Kolos, 1983.-223s.

2. A. Zh. Sagyndikova, N. T. Isembergenov, B. KanayEnergy-saving installation for grain Drying// Works "the role and place of young scientists in the implementation of the new economic policy of Kazakhstan" Inter. Satp. Readings, volume 4, Almaty.2015.p.195-198

3.Author's certificate of the Republic of Kazakhstan No. 91438 "Grain drying plant", A. Zh. Sagyndikova, N. T. Isembergenov, K. N. Taisarieva, Astana 2014.

4. A. Mitkov Theory of experiment.-Rus.:Dunav press, 2011,227 p

5. V. V. Morozov, N. M. MaksimovComparative analysis of designs of bunker grain dryers of foreign and domestic production. Velikiye Luki state agricultural Academy, Russia,Velikiye Luki,2014. 29-35 p.

6.Author's certificate of the Republic of Kazakhstan No. 93979 "Installation for grain drying using induction heating", Sagyndikova A. Zh., isembergenov N. T.

7.MohamedHemisatal, journal «BiosystemsEngineering» №1 12, 2012 стр.202209 , (journalhomepage: www.elsevier.com/locate/issn/15375110).

8. Message of the President of the Republic of Kazakhstan NursultanNazarbayev to the people of Kazakhstan of January 17, 2016 "Kazakhstan's way - 2050. Common goal, common interests, common future"; http6//www.akorda.kz

9. Nations encyclopedia. Asia and Pacific.Kazakhstan Agriculture.

10. OECD (2013), Agricultural Policy Monitoring and Evaluation 2013: OECD Countries and Emerging Economies, OECD Publishing. http://dx.doi.org/10.1787/agr_pol-2013-en

11. RFCA Ratings (2014) Analysis of Crop Production in Kazakhstan. Report.

12. Analysis of production performance of agricultural and food products of the CU and the EEC member-countries for 2013-2015"

13. S.S.Ospanov, A.Y. Kaliyeva, R.T. Dulambaeva, Zh.Y. Aubakirova, T.P.Tabeev. Competitiveness of the Agricultural Sector as a Factor in Improving Food Security in the Conditions of Globalization. Review of European Studies; Vol. 7, No. 7; 2015

14. The U.S. Department of Commerce's International Trade Administration. Retrieved from http://export.gov/kazakhstan-agriculture

15.OECD (2013), OECD Review of Agricultural Policies: Kazakhstan 2018, OECD Publishing. http://dx.doi.org/10.1787/9789264191761-en

16. A....Sagyndikova, A.Sh.Dzhamburshyn, A.K.Atyhanov, H.BeloevMechanics of the Movement of Grain on a Helical Surface in the Induction Dryer.Journal of Engineering and Applied Science.Year: 2015 | Volume: 10 | Issue: 8 | Page No.: 267-269. ISSN:1816949X

17.V.I.Kovbasyuk. Energy-saving drying and its application.International Journal of Advanced Trends in Computer Science and Engineering(IJATCSE), https://www.researchgate. net/publication/282891772_Energosberegausaa_s uska_i_ee_primenenie

18.F.Ya.Rudik, N.L.Morgunova, E.A.Faust, E.S. Krasnikova, Technology and means of mechanization for grain processing. International Journal of Advanced Trends in Computer Science and Engineering (IJATCSE),https://www.researchgate.net/publicati on/341138163_Tehnologia_i_sredstvo_mehaniza cii_dla_obrabotki_zerna 
19.I.Kondratenko. induction heating of flat steels.

International Journal of Advanced Trends in Computer Science and Engineering (IJATCSE)

https://www.researchgate.net/publication/319762

264_indukcionnyj_nagrev_ploskogo_prokata_met allov

20. I. KONDRATENKO. INDUCTION HEATING OF A MOVING STRIP BY CURRENT CIRCUITS.JOURNAL OF ADVANCED TRENDS IN COMPUTER SCIENCE AND ENGINEERING (IJATCSE), HTTPS://WWW.RESEARCHGATE.NET/PUBLICATION/31 9762191_INDUKCIONNYJ_NAGREV_DVIZUSEJSA_PO LOSY_TOKOVYMI_KONTURAMI

21. I.L. Boshkova. N.V. Volgusheva.Cyclic microwave drying of a dense layer of grain materials.International Journal of Advanced Trends in Computer Science and Engineering (IJATCSE),

https://www.researchgate.net/publication/325860 841_CIKLICESKAA_MIKROVOLNOVAA_SU SKA_PLOTNOGO_SLOA_ZERNOVYH_MAT ERIALOV 